NASA Technical Memorandum 88859

\title{
Composite Space Antenna Structures: Properties and Environmental Effects
}

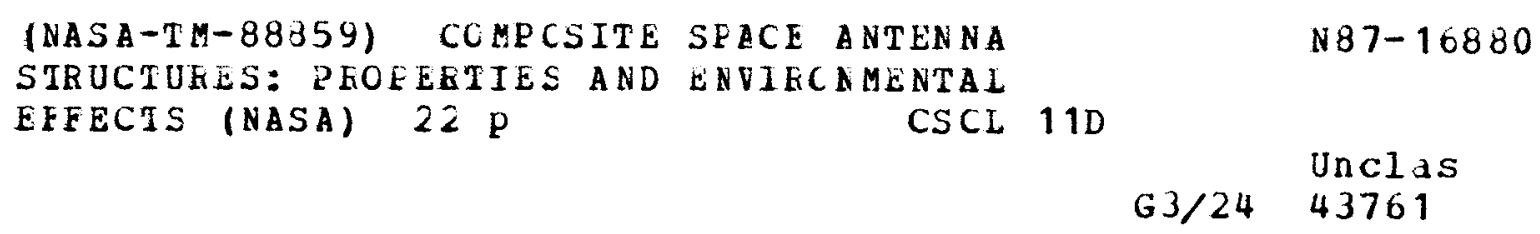

Carol A. Ginty

Lewis Research Center

Cleveland, Ohio

and

Ned M. Endres

Sverdrup Technology, Inc.

Lewis Research Center

Cleveland, Ohio

Prepared for the

18th International SAMPE Technical Conference

Seattle, Washington, October 7-9, 1986 


\title{
COMPOSITE SPACE ANTENNA STRUCTURES: PROPERTIES \\ AND ENVIRONMENTAL EFFECTS
}

\author{
Carol A. Ginty \\ National Aeronautics and Space Administration \\ Lewts Research Center \\ Cleveland, Ohio 44135
}

and

Ned $M$. Endres

Sverdrup Technology, Inc.

Lewis Research Center

Cleveland, Ohio 44135

\section{SUMMARY}

The thermal behavior of composite spacecraft antenna reflectors has been investigated with the Integrated Composites Analyzer (ICAN) computer code. Parametric studies have been conducted on the face sheets and honeycomb core which constitute the sandwich-type structures. Select thermal and mechanical properties of the composite faces and sandwich structures are presented graphically as functions of varying fiber volume ratio, temperature, and moisture content. The coefficients of thermal expansion are discussed in detall since these are the critical design parameters. In addition, existing experimental data are presented and compared to the ICAN predictions.

\section{INTRODUCTION}

NASA Lewis Research Center is currently conducting studies associated with several national space programs. One such project is the Advanced Communication Technology Satellite (ACTS) scheduled for launch in 1989 (fig. 1). The present design of the ACTS incorporates five antennae in the form of two main reflectors and three subreflectors. Used in this configuration for communication purposes, the antenna reflectors must be designed for tightly controlled thermal distortions, since relatively small mismatches in thermal expansions and thermal conductivities can produce structural deformations which would adversely affect the transmitted signal.

As a result, sandwich-type structures consisting of composite face sheets and honeycomb cores are often selected for the design of the antenna reflectors since the composite laminate face sheets can be optimized to provide a coefficient of thermal expansion of zero. However, due to the lack of available composite mechanical and thermal properties, it is quite difficult to conduct the structural and thermal analyses required to verify the design.

Therefore, the computer code ICAN (Integrated Composites Analyzer) was used to conduct a parametric study of the composite laminate face sheets and sandwich structures proposed for the design of the satellite. In particular, ICAN, which is a portable program developed at Lewis Research Center to analyze/design fiber composite structures, was used to analyze the main reflector of the satelifte which is the topic of this paper. 
Five material systems were selected as candidates for the face sheets: four high-modulus fibers, low-cure temperature resins and one hybrid. Parametric studies were conducted with varlous fiber volume ratios using quasiisotropic laminate configurations of $[0 / 90] \mathrm{s},[0 / \pm 60] \mathrm{s}$, and $[0 / \pm 45 / 90] \mathrm{s}$ with a nominal ply thickness of $0.005 \mathrm{in} .(0.127 \mathrm{~mm})$. The laminates were analyzed with thermal and hygral conditions typical for composite structures in a geosynchronous space orbit. The temperature varies from $250^{\circ} \mathrm{F}\left(121^{\circ} \mathrm{C}\right)$ when facing the sun to $-250^{\circ} \mathrm{F}\left(-157^{\circ} \mathrm{C}\right)$ when away from the sun (cryogenic). Likewise, the moisture content varies from 1 percent on earth to 0 percent in space. In addition, analyses were conducted for room temperature/dry conditions to establish a baseline for comparison.

From the results of the study, the selection of suitable face sheet configurations was based upon a prescribed criteria: zero or near zero coefficient of thermal expansion. ICAN was then used to analyze the sandwich structures comprised of the select laminate face sheets with an aluminum honeycomb core. The final selection of the sandwich configuration for the design of the main antenna reflector was made using the same prescribed criteria.

Several ICAN predicted thermal properties (coefficlent of thermal expansions, thermal conductivity and heat capacity) and mechanical properties (elastic and shear moduli and Poisson's ratio) are presented graphically as a function of fiber volume ratio, temperature, and molsture for both the composite face sheets and sandwich structures. These results are also compared to limited experimental data generated in the ACTS program. In addition, the constituent properties of the composite systems, the analyses methods incorporated in the ICAN code, and problems related to composites in the space environment are discussed.

\section{ICAN: INTEGRATED COMPOSITES ANALYZER}

The computer code ICAN (Integrated Composites Analyzer) has been developed to analyze/design fiber composite structures (ref. 1). The program includes composite mechanics theories which resulted from extensive research conducted over the past 15 years at Lewis Research Center. ICAN is a synergistic combination of two other NASA Lewis developed codes: MFCA (Multilayered Fiber Composites Analysis) and INHYD (Intraply Hybrid Composite Design).

MFCA (ref. 2) is efficient in predicting the structural response of multilayered fiber composites given the constituent material properties, fabrication process, and composite geometry. INHYD (ref. 3) incorporates several composite micromechanics theories, intraply hybrid composite theories, and a hygrothermomechanical theory to predict the mechanical, thermal, and hygral properties of intraply hybrid composites. ICAN utilizes the micromechanics design of INHYD and the laminate theory of MFCA to build a comprehensive analysis/design capabllity for structural composites. Features unique to ICAN include: (1) ply stress-strain influence coefficients, (2) microstresses and microstress influence coefficients, (3) stress-concentration factors at a circular hole, (4) predictions of probable delamination locations around a circular hole, (5) Poisson's ratio mismatch details near a straight free edge, (6) free edge stresses. (7) material cards for the general purpose finite element analysis programs NASTRAN (COSMIC and MSC) and MARC, (8) laminate fallure stresses based upon first ply fallure and fiber fracture criteria, with and without hygro- 
thermal degradation, (9) transverse shear stresses and normal stresses, (10) explicit specification of intraply layers, and (11) delamination of these layers due to adjacent ply relative rotation.

In addition, ICAN possesses another unique feature in its resident data bank which houses the constituent (fiber/matrix) properties. The fiber is entered into the data bank as a four character coded name followed by the physical, elastic, thermal, and strength related properties. Likewise, the matrix is entered with a four character coded name with the same properties and an additional card for miscellaneous properties. Years of literature searches and in-house experimental programs on materials characterization have resulted in the compllation of the existing data bank. Designed to be open-ended, the user has the ability to add new constituent materiais to the data bank as they appear in the literature.

Input parameters of ICAN include: selection of material system, fiber volume ratio (FVR), laminate configuration, fabrication factors, and environmental and loading conditions. A sample input data set is shown in figure 2 where the parameters are transparent to the user. Also shown, are the properties of the constituents (used in the sample) as they appear in the data bank.

The complete documentation of ICAN with compiled listing, user instructions, programmer's manual and sample cases for each option is available in reference 4 . The program will soon be made available through COSMIC-Computer Software Management and Information Center, Suite 112, Barrow Ha 11, Athens, Georgia 30602 .

\section{PARAMETRIC STUDIES OF COMPOSITE FACE SHEETS}

Reflectors used for communication satelites must be designed for tightly controlled thermal distortions. A slight deviation in the geometry of the design caused by mismatches in coefficient of thermal expansions (CTE) can produce significant distortion in the satellite's transmitted signal to earth. In fact, a requirement for the ACTS reflectors is that the surface must be fabricated to an accuracy of $\pm 0.002 \mathrm{in}$. $(0.0508 \mathrm{~mm})$ RMS (Root Mean Square).

To achieve this requirement, the first phase of the main antenna reflector design is to select a composite material system from which to fabricate the face sheets. The face sheets are initially designed since the laminate can be configured such that the CTE is either zero or negative, which is the primary design criterla for the reflector. ICAN was used to analyze five candidate composite systems for the face sheet structures. Two of these composite systems. Thornel 300 graphite fiber/Fiberite 934 resin and Kevlar/epoxy are widely used and have been successful in other aeronautics/space applications. Two other composite systems, which are relatively new in the composite community, Thornel carbon fiber P75 and Thornel graphite fiber P100 with Fiberite 934 resin, were selected for consideration since they were marketed as low CTE materials. Finally, one hybrid was selected for the study using the Kevlar and P75 composites. Each composite system was modeled with ICAN using FVRs of 0.5, 0.6 and 0.7 . While most current materials are supplied with a FVR of 0.62 , often the fiber content in prepregs is batch dependent. Therefore, three FVRs were used to account for this. With a ply thickness of $0.005 \mathrm{in}$. $(0.127 \mathrm{~mm})$, three quasi-isotropic laminate configurations were modeled: 4 ply [0/90]s, 6 ply $[0 / \pm 60] \mathrm{s}$, and 8 ply $[0 / \pm 45 / 90] \mathrm{s}$. ICAN ana $7 y z e d$ each laminate at room 
temperature $\left(70^{\circ} \mathrm{F}\left(21^{\circ} \mathrm{C}\right)\right)$, high temperature $\left(250^{\circ} \mathrm{F}\left(121^{\circ} \mathrm{C}\right)\right)$, and cryogenic temperature $\left(-250^{\circ} \mathrm{F}\left(-157^{\circ} \mathrm{C}\right)\right)$ with moisture contents of 0 and 1 percent. The cure temperature used for the analysis was $350^{\circ} \mathrm{F}\left(177^{\circ} \mathrm{C}\right)$ since all material systems use epoxy resins.

The parametric study for the face sheets alone generated 360 runs of the ICAN program, resulting in the mechanical and thermal properties at the space temperature range which are required for further analysis and design. For the sake of brevity, only a sampling of the predicted properties are presented.

To eliminate unsultable candidate composite systems from the study, the zero CTE design criterla was employed. The in-plane CTEs predicted by ICAN for all candidate materials are shown graphically in figs. 3 to 7 for the [0/90]s laminate configuration as a function of FVR, temperature, and moisture. This laminate configuration is used since it has the least amount of plies yielding the lightest laminate in the study. Since ACTS is scheduled to be transported and deployed via shuttle, structural weight has emerged as another design criteria.

Figure 3 shows the CTE for the Thornel 300/Fiberite resin (T300/934) composite. Prior to the analysis, T300/934 was a potential choice for the face sheets due to its widespread usage on existing aeronautics/space structures. However, for all temperature ranges, the CTE is positive. Thus, T300/934 is eliminated from the study.

Kevlar (Kevl) prepreg is avallable from several vendors, each using different resins. For the ICAN analysis, the constituent properties of the Fiberite 934 resin were used. The CTE for Kev1/934 is presented in figure 4. For the thermal range shown, the CTE becomes negative at a FVR of 0.63 at the cryogenic temperature and at the high temperature, a FVR of 0.66 is required to generate a negative CTE. Therefore, to design the main reflector face sheets from Kev1/934, a prepreg with 66 percent FVR is needed. While it is probably possible to manufacture this prepreg, the sensitivity of the main reflector requires a greater margin of safety. Based upon this, therefore, Kev1/934 is also eliminated from the study. Before analyzing the high-modulus fiber composites, the constituent properties for the Thornel P75 and P100 fibers were collected and inserted into the ICAN data bank. Vendor data sheets provide approximately half of the required 17 properties. The others are substituted with those from existing high-modulus fibers in the data bank. The CTE results are shown in figures 5 and 6 for the P75/934 and P100/934 systems, respectively. Since the composite was marketed as a low CTE material, the results come as no surprise. In figure 5, the P75/934 CTE becomes negative at a FVR of approximately 0.55, which is an attractive design quality. In figure 6 , the P100/934 exhibits negative CTE for all given conditions. Due to this behavior, both materials are candidates for the final face sheet design.

As previously mentioned, one composite hybrid material system was selected for the study. The hybrid consisted of 60 percent Kev1/934 and 40 percent P75/934. It was analyzed under the same conditions and the ICAN predicted results are shown in figure 7. The CTE becomes negative at a FVR of 0.62 . The hybrid does meet the design requirements; however, when compared to the P75/934 and P100/934 results it is no longer a competitive candidate. In addition, the fabrication procedure for hybrids is more complex, making hybrids more susceptible to inadvertent errors such as misalignment of tape width and tape positioning. 
The CTEs behaved in the same manner for all material systems. In particular, three trends were observed regarding the environmental conditions. For a given laminate: (1) the CTE is greater when 1 percent moisture is present, especially at higher temperatures, (2) the CTE increased with increasing temperature, and (3) as the FVR increases, the CTE decreases. Recalling that the matrix for all the composites is an epoxy resin, this behavior is expected.

Thus, based upon the ICAN results, P75/934 and P100/934 are the final material candidates. Although P100/934 did have all negative CTEs, the exorbitant price of the material (more than three times per pound the cost of P75/934) eliminated it from the survey due to cost restraints in the ACTS program; therefore, P75/934 was chosen for the final design. Additional properties predicted by ICAN for the P75/934 laminate are presented in figures 8 to 12 . Figure 8 displays the thermal conductivity $(K)$ for various FVRs. As temperature and FVR increase, $K$ increases. Moisture contributes to increasing $K$ which is most noticeable at $250^{\circ} \mathrm{F}\left(121^{\circ} \mathrm{C}\right)$. The heat capacity (C) is shown in figure 9 . Independent of direction and laminate configuration, $C$ increases with temperature. In the cryogenic range, FVR has little effect on $C$, but as the temperature increases, $C$ decreases with increasing FVR. As was observed for the other thermal properties, moisture increases C, particularly in the higher thermal range.

The mechanical properties are presented in figures 10 to 12 . Shown in Figure 10, the elastic modulus, $E c x x(E c x x=E c y y)$, is for all practical purposes independent of temperature and molsture. For a prepreg having a FVR of $0.62 \pm 0.02$, E ranges from 23 to $24 \mathrm{mpsi}(1.58$ to $1.62 \times 1011 \mathrm{GPa})$ ). The shear modulus decreases with moisture for all temperatures in figure 11 . As a result, the shear modulus will be greater in a space environment where moisture is known not to be a problem. The shear modulus increases substantially with decreasing temperature. When facing the sun during orbit, the shear modulus is almost 1.7 times smaller than that in the cryogenic portion of orbit. Finally, in figure 12, Poisson's ratio (NU) for the P75/934 laminate is plotted. As FVR increases, NU decreases. Once again, for each temperature analyzed, moisture decreases the value of NU.

For the communication satellite, the critical design parameter is the CTE. However, depending on the structure and its function, any one of these properties discussed and how they react under the environmental conditions can be of critical importance in the design. All of these properties are required for additional detalled mechanical and thermal analyses. In fact, ICAN generates the material cards for finite element analysis codes such as NASTRAN and MARC.

\section{PARAMETRIC STUDIES OF THE SANDWICH STRUCTURE}

The antenna reflector is designed as a symmetric sandwich with composite laminate face sheets, adhesive layers, and a honeycomb core (fig. 13). When investigating the face sheets, the primary design criteria was the mismatch in CTEs between fiber and matrix and how the space environment would affect it. For the sandwich structure, ICAN is used to investigate the mismatch in CTEs between the sandwich components: face, adhesive, and core. Once again, the zero (or near zero) CTE design criteria is enforced so that the sandwich can meet the $0.002 \mathrm{in} .(0.0508 \mathrm{~mm})$ distortion requirement. 
The face sheets have been selected and are [0/90]s P75/934 laminates. The adhesive layers are modeled in ICAN as individual plies. Prior to the analysis, the material properties for the adhesive were obtained from the vendor and a corresponding fiber and matrix were created and added to the data bank. Two honeycomb cores were selected for the parametric study: Hexcel-Aluminum and DuPont-Nomex. In this paper, only the aluminum honeycomb will be discussed.

ICAN was designed for the analysis of continuous fiber composites. Therefore, a technique was developed to transform the honeycomb core into an equivalent homogeneous material which, in turn, could be transformed into the fiber and matrix format required for the data bank. This technique is described in detall in reference 5 . Briefly, a set of simple equations were generated to predict equivalent properties for a honeycomb core made from any material. A procedure was then developed to use these approximate equations in conjunction with composite mechanics in order to simulate sandwich thermal/structural behavior. This procedure is embedded in the ICAN code as a separate version and is identified as ICAN/SCS for Sandwich Computational Simulation. At this time, this special version of ICAN is not publicly avallable, but will be in the near future.

Using ICAN/SCS, the parametric study was conducted on the sandwich with an emphasis on the thermal conditions of a geosynchronous orbit. Therefore, the ICAN results for the sandwich are presented graphically as a function of temperature for both 0 and 1 percent moisture. The thermal properties for the sandwich are predicted in figures 14 to 17 . The critical property, CTE, is shown in figure 14. The in-plane CTEs are approximately $1.3 \mu$ in $/$ in ${ }^{\circ} \mathrm{F}$ which is acceptable for the antenna reflector design. Although moisture has no effect on the CTE, the honeycomb core produces a slight variation in the in-plane values. Since the results are plotted as a function of temperature, note that the in-plane CTE for the sandwich structure does not vary with the temperatures encountered in space. On the other hand, the through-thethickness CTE is considerably greater (about 10 to 20 times) and increases significantly with increasing temperature. The thermal conductivity $(K)$ is shown for the longitudinal and transverse directions in figures 15 and 16 respectively. Due to the inherent properties of the aluminum honeycomb, there is a small variation in the values. $K$ is slightly higher in the longitudinal direction. $K$ is also more sensitive to temperature than the CTE, particularly at the higher range. Finally, in figure 17 , the heat capacity (C) is independent of moisture content, but very sensitive to temperature.

Graphical results for the mechanical properties (elastic and shear moduli) are shown in figures 18 and 19, respectively. The elastic modulus (E) in figure 18 appears to be sensitive to higher temperatures, causing a decrease in value. However, the selected scale is an expanded one, so in actuality, $E$ is not that sensitive to temperature. As was observed for the face sheets, $E$ for the sandwich structure also decreases with moisture. The shear modulus in figure 19 does reflect a sensitivity to higher temperatures producing a lower value for the shear modulus. The shear modulus decreases substantially with increasing temperature as expected from the face sheet shear moduli (fig. 11).

Using ICAN, the proposed design of the antenna reflector was modeled as a sandwich structure. The behavior of the structure was then investigated by employing the thermal and hygral conditions of a space environment. According 
to the properties presented, herein, this particular design meets the specifications for a communication satelite. Now, these results for the main reflector can be used in additional studies on the entire satelite configuration. As was previously mentioned, ICAN has been established as an effective tool for the preliminary design of composite structures. In reference 6, ICAN results are compared to data from several experimental programs. The correlation of the properties rendered confidence in the predictive capabilities in ICAN. For the ACTS project, a parallel experimental program (ref. 7 ) is being conducted, from which select room temperature properties for the P75/934 laminate face sheets are presented in table 1 along with the ICAN predictions. The good correlation which exists yields additional confidence in the ICAN results.

\section{SUMMARY AND CONCLUSIONS}

The thermal behavior of the main reflector of the ACTS was investigated using the integrated composite mechanics incorporated in the ICAN computer code. The impetus for this parametric study is the lack of an existing data base on the hygrothermomechanical properties of composites, particularly in a space environment. For the ACTS, properties were required first for the laminate face sheets and then for the sandwich structure which simulates the main reflector design. The thermal and mechanical properties predicted by ICAN for the face sheets and sandwich were presented as a function of FVR and temperature, respectively, with an emphasis on the CTE. The CTE is the critical design parameter since relatively small deviations in the CTE can produce a significant distortion in the transmitted signal, which is the primary function of ACTS.

The results presented and discussed demonstrate that ICAN can be used to perform parametric studies on composite space structures producing relatively accurate results for design purposes. The costs along with user and computational times required to generate these properties are trivial in comparison to an experimental effort of the same size. The method used herein to design the composite sandwich of the main antenna reflector can be used to design other space structures, as we 11, provided the parameters have been defined and the critical properties are known.

\section{REFERENCES}

1. Murthy, P.L.N.; and Chamis, C.C.: ICAN: Integrated Composites Analyzer. AIAA Paper 84-0974, May 1984.

2. Chamis, C.C.: Computer Code for the Analysis of Multilayered Fiber Composites-User's Manual. NASA TN D-7013, 1971.

3. Chamis, C.C.; and Sinclair, J.H.: INHYD: Computer Code for Intraply Hybrid Composite Design. A Users Manual. NASA TP-2239, 1983.

4. Murthy, P.L.N.; and Chamis, C.C.: Integrated Composite Analyzer (ICAN); Users and Programmers Manua 1. NASA TP-2515, 1986.

5. Chamis, C.C.; Aiello, R.A.; and Murthy, P.L.N.: Composite Sandwich Thermostructural Behavior: Computational Simulation. 27th Structures, Structural Dynamics and Materials Conference, AIAA, 1986, pp. 370-381. 
6. Ginty, C.A.; and Chamis, C.C.: ICAN: A Versattle Code for Predicting Composite Properties. NASA TM 87334, 1986.

7. Bowles, K.J.; and Vannucc1, R.D.: High Modulus Fibers and Their Composites. To be presented at the ASTM Test Methods and Design Allowables for Fiber Composites: Second Symposium, Phoenix, AZ, Nov. 3-4, 1986. 
OFIGINAL PAEE
MF POOR QUALTN

TABLE 1. - SELECT ROMM TEMPERATURE PROPERTIES FOR 075/934 LAMINATES LEWTS EXPERIMENTAL VERSIIS ICAN PREDICTIONS

\begin{tabular}{|c|c|c|c|c|c|c|}
\hline \multirow{2}{*}{$\begin{array}{c}\text { Material } \\
\text { properties }\end{array}$} & \multicolumn{5}{|c|}{ Laminate confiquration } \\
\cline { 2 - 7 } & \multicolumn{2}{|c|}{$[078$} & \multicolumn{2}{|c|}{$[0 / 90]_{5}$} & \multicolumn{2}{c|}{$[0 / \pm 6 n]_{5}$} \\
\cline { 2 - 7 } & Experimental & ICAN & Experimental & ICAN & Experimental & ICAN \\
\hline $\begin{array}{c}\text { Failure stress } \\
\text { N/mm2 (ksi) } \\
\text { Failure strain } \\
\text { mm/nm (in./in.) }\end{array}$ & $862(125)$ & $938(136)$ & $414(60)$ & $476(69)$ & $331(48)$ & $324(47)$ \\
$\begin{array}{c}\text { Elastic modulus, } \\
\text { GPa (mpsi) } \\
\text { Poisson's ratio }\end{array}$ & 0.0031 & 0.0030 & 0.0028 & 0.0030 & 0.0031 & $n .0 n 3 n$ \\
\hline
\end{tabular}


C.PIGINAL PRE: ?

OF POOR QU⿴囗十)

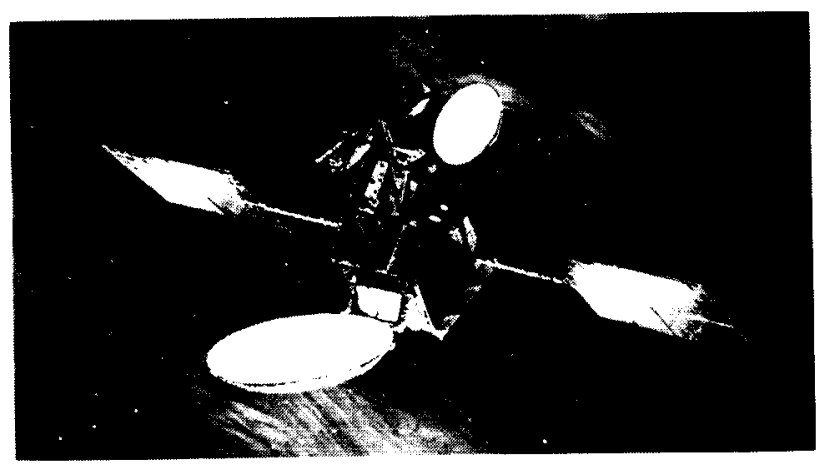

Figure 1. - ARTIST'S CONCEPTUAL DRAWING OF THE ADVANCED COMMUNICATION TECHNOLOGY SATELLITE (ACTS). 


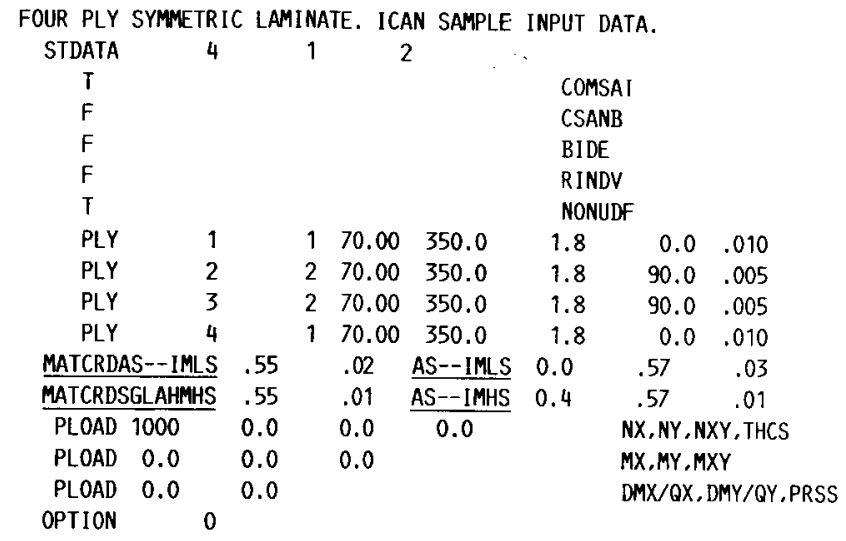

INPUT DATA SET

AS-- GRAPHITE FIBER

FP $10000 \quad 0.300 E-03 \quad 0.630 E-01$

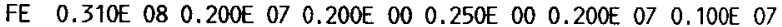

FT -0.550 -06 0.560 E-05 0.580 E $03 \quad 0.580$ E $02 \quad 0.170 E \quad 00$

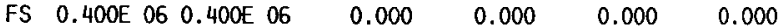

SGLA S- GLASS FIBER

FP $204 \quad 0.360 \mathrm{E}-03 \quad 0.900 \mathrm{E}-01$

FE $\quad 0.124 \mathrm{E} \quad 08 \quad 0.124 \mathrm{E} \quad 08 \quad 0.200 \mathrm{E} \quad 00 \quad 0.200 \mathrm{E} \quad 00 \quad 0.517 \mathrm{E} \quad 07 \quad 0.517 \mathrm{E} \quad 07$

FT $0.280 E-05 \quad 0.280 E-05 \quad 0.750 E \quad 010.750$ E 010.170 E 00

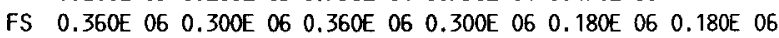

IMLS INTERMEDIATE MODULUS LOW STRENGTH MATRIX

MP $0.460 E-01$

ME $\quad 0.500 E$ O6 $0.410 E \quad 00 \quad 0.570 E-04$

MT $0.125 E \quad 010.250 E \quad 00$

$\begin{array}{lllllllllllllllll}\text { MS } & 0.700 E & 04 & 0.210 E & 05 & 0.700 E & 04 & 0.140 E-01 & 0.420 E-01 & 0.320 E-01 & 0.320 E-01\end{array}$

MV $0.225 E \quad 00 \quad 0.420 E \quad 03$

HMHS HIGH MODULUS HIGH STRENGTH MATRIX

MP $0.450 E-01$

ME $\quad 0.750 E$ O6 $0.350 E$ DO $0.400 E-04$

MT $0.125 E \quad 010.250 E 00$

MS $0.200 E \quad 05 \quad 0.500 E$ O5 $0.150 E$ E $05 \quad 0.200 E-01 \quad 0.500 E-01 \quad 0.400 E-01 \quad 0.400 E-01$

MV $0.225 E \quad 00 \quad 0.420 E \quad 03$

IMHS INTERMEDIATE MODULUS HIGH STRENGTH MATRIX

MP $0.440 E-01$

ME 0.500 E $06 \quad 0.350 E \quad 00 \quad 0.360 E-04$

MT $0.125 E \quad 010.250 E$ O0

$\begin{array}{llllllllllllll}\text { MS } & 0.150 E & 05 & 0.350 E & 05 & 0.130 E & 05 & 0.200 E-01 & 0.500 E-01 & 0.350 E-01 & 0.350 E-01\end{array}$

MV $0.225 E \quad 00 \quad 0.420 E \quad 03$

RESIDENT DATA BANK ECHO

Figure 2. - SAMPLES OF THE INPUT DATA SET AND the CONSTITUENT PRoperties IN THE DATA BANK. 

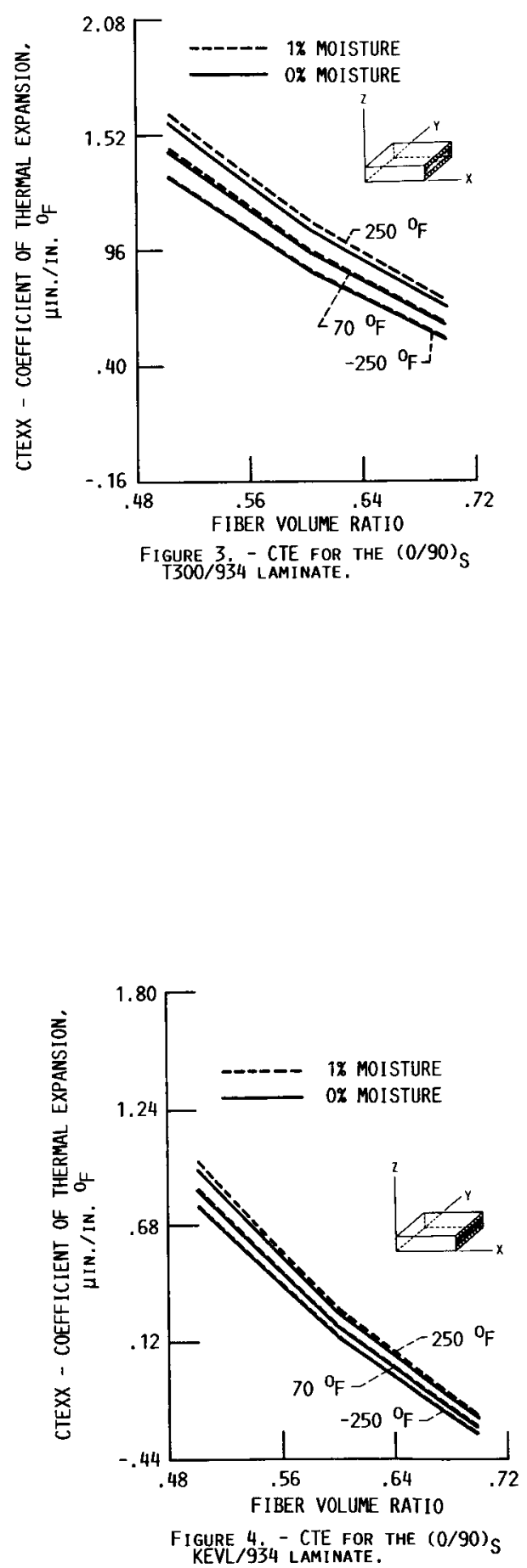

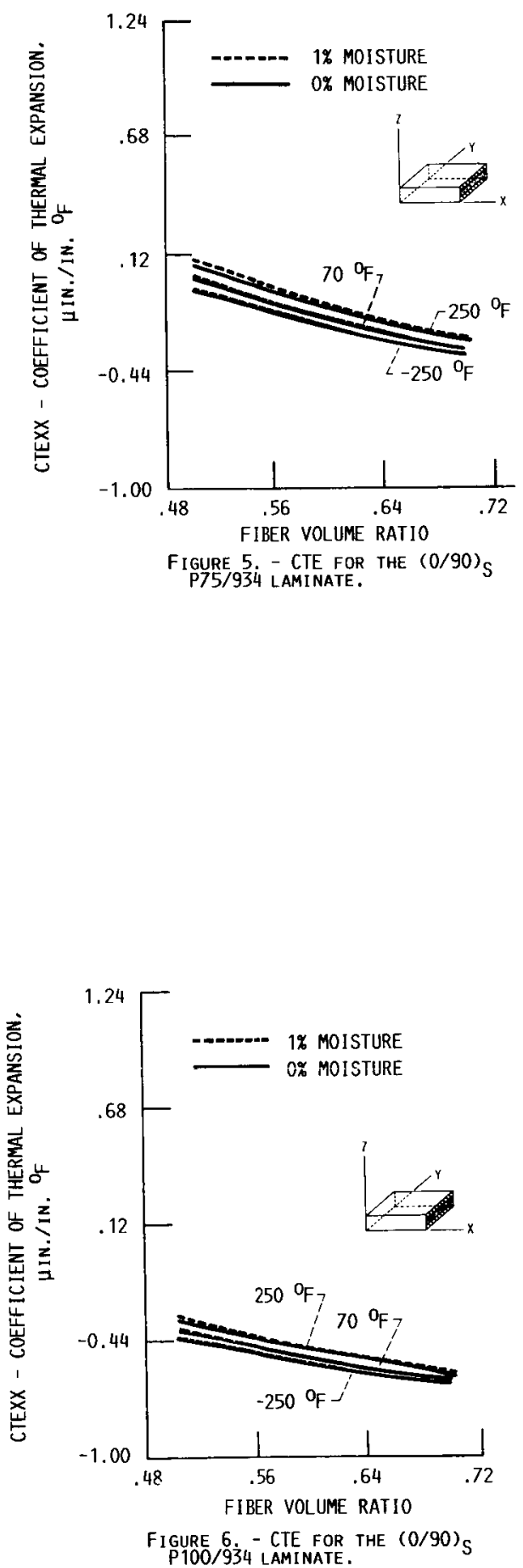


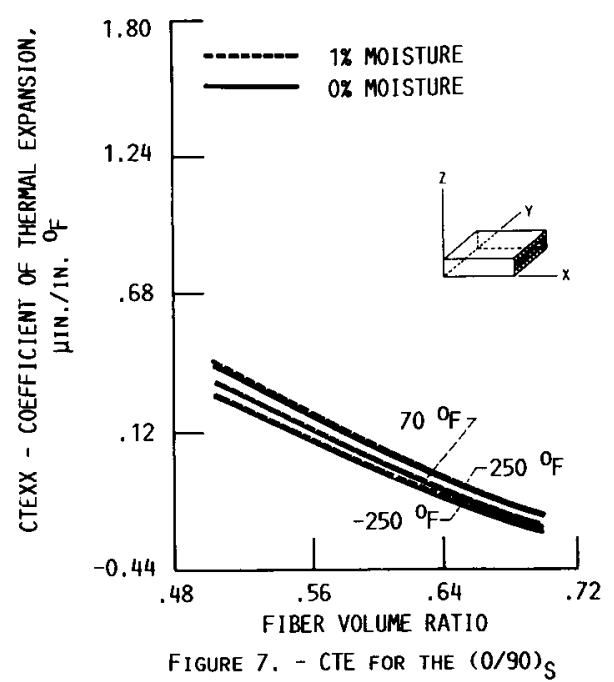

KEVL/934//P75/934 HYBRID.

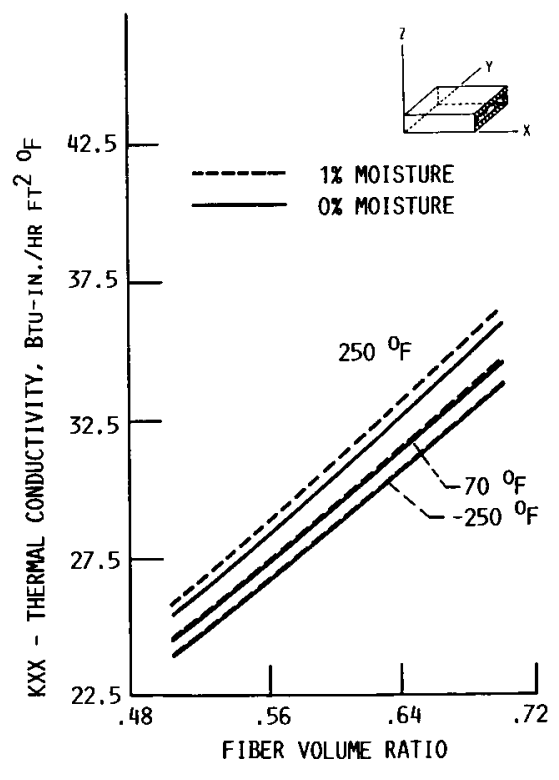

FIGURE 8. - THERMAL CONDUCTIVITY

FOR THE $(0 / 90)_{S}$ P75/934 LAMINATE

WHERE $1 \mathrm{BTU}$-IN./HR FT $^{2}$ OF

$=3.44482 \times 10^{-4} \mathrm{CAL} / \mathrm{s} \mathrm{cM}{ }^{0} \mathrm{C}$. 


\section{ORIGINAL PACE IS OF POOR QUALITY}
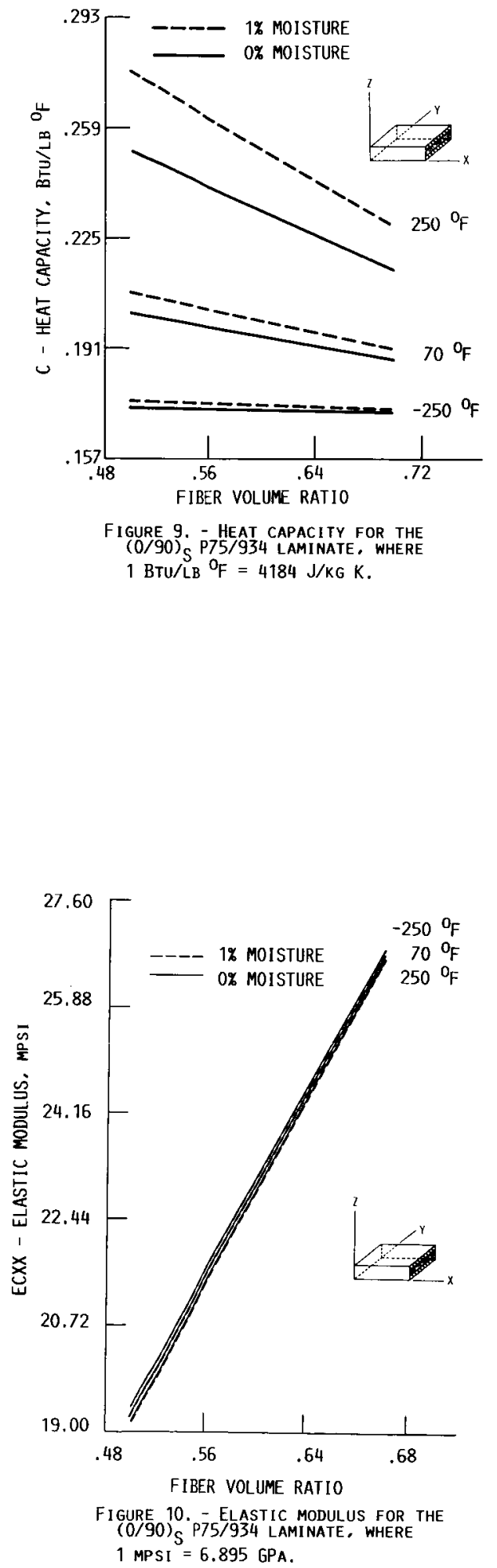

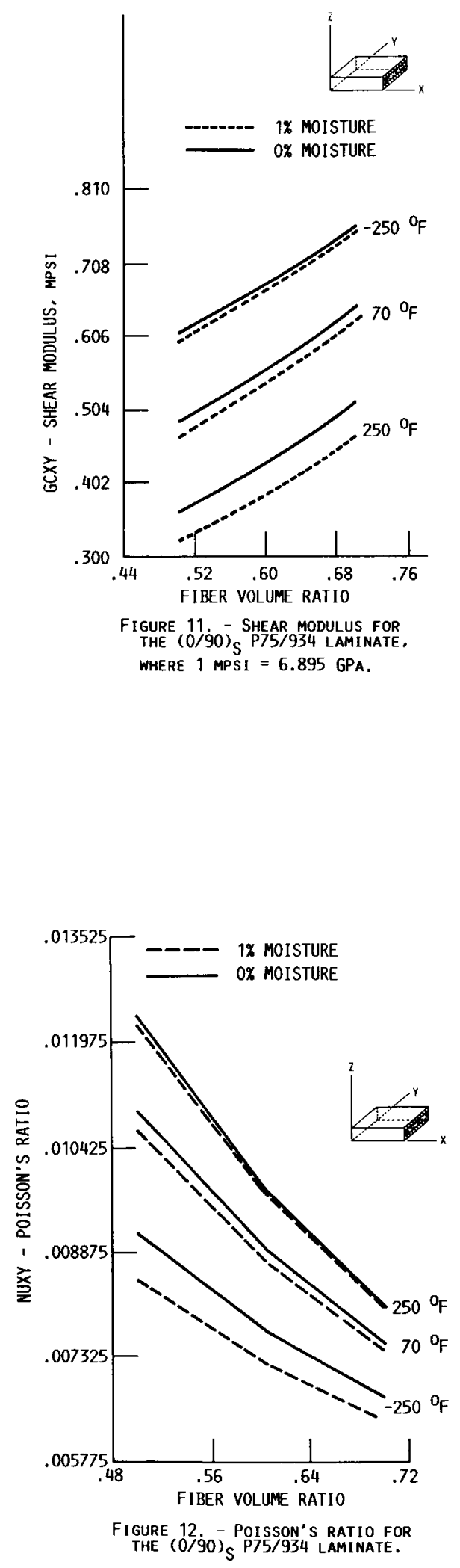


\section{ORIGINAL PAGE. IS \\ OF POOR OUALITY}

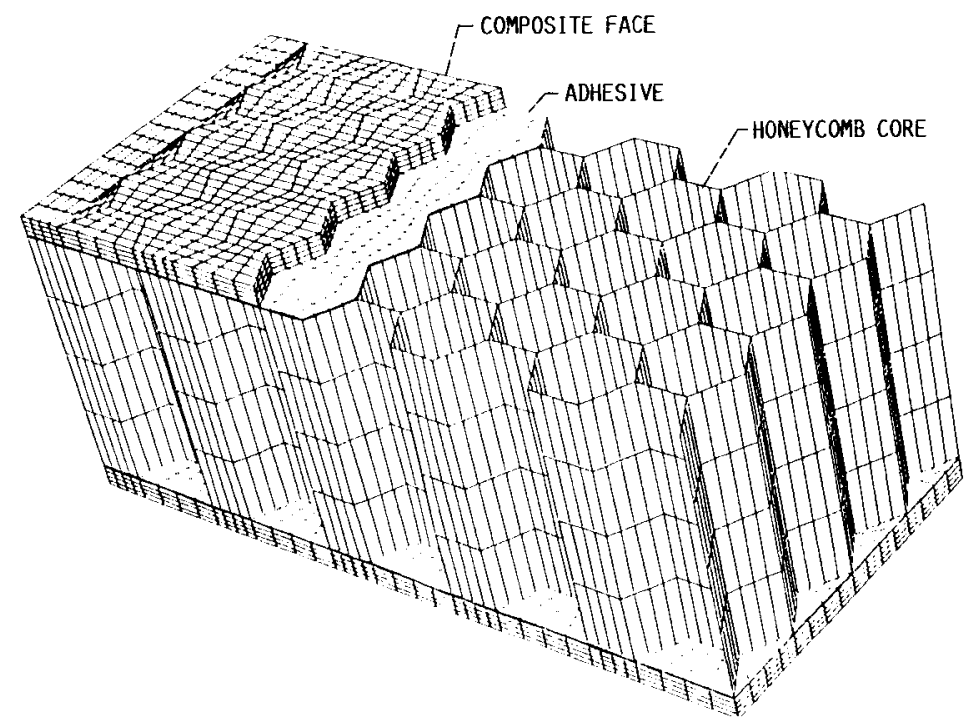

Figure 13. - 3-D Finite ELEMENT MODEL OF IHE COMPOSITE SANDWICH WITH A HONEYCOMB CORE.

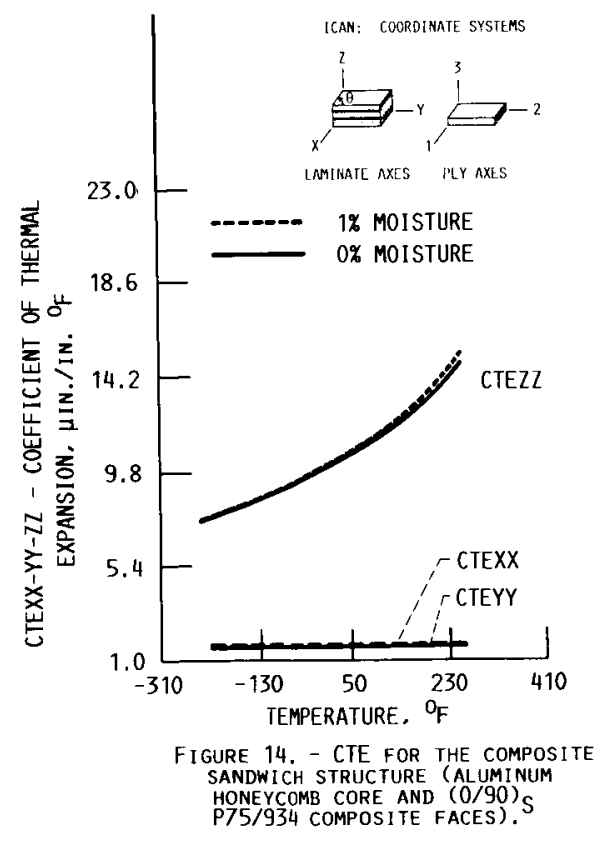




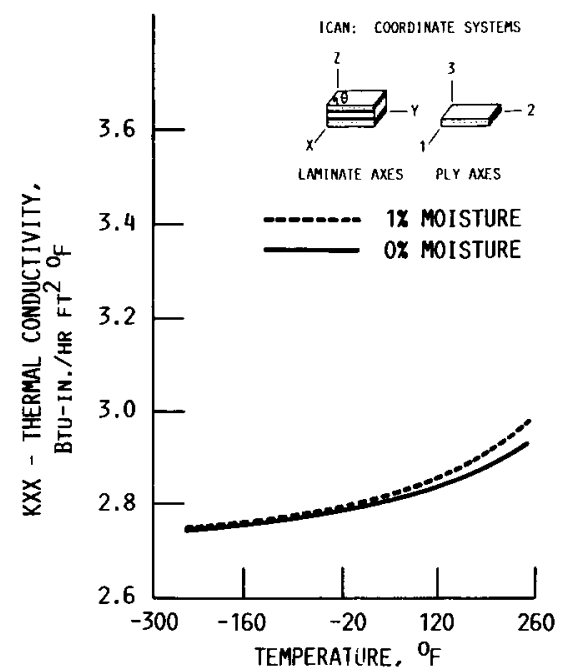

Figure 15. - THERMAL CONDUCTIVITY

FOR THE COMPOS ITE SANDWICH STRUCTURE (ALUMINUM HONEYCOMB CORE AND $(0 / 90)_{S}$ P75/934 COMPOSITE FACES)

WHERE 1 BTU-IN./HR FT ${ }^{2}{ }^{\circ} \mathrm{F}$

$=3.44482 \times 10^{-4} \mathrm{CAL} / \mathrm{S} \mathrm{cM}{ }^{0} \mathrm{C}$.

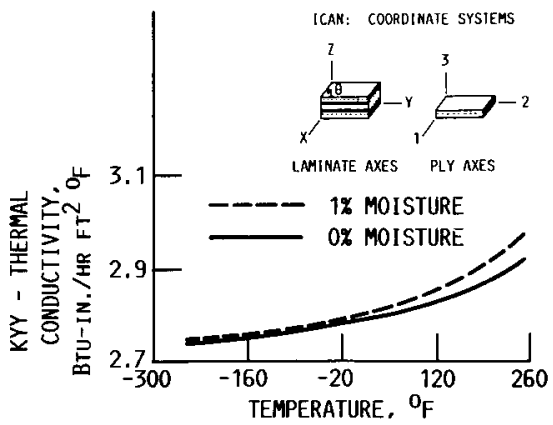

FIGURE 16. - THERMAL CONDUCTIVITY FOR THE COMPOS ITE SANDWICH STRUCTURE (ALUMINUM HONEYCOMB CORE AND $(0 / 90)_{S}$ P75/934 COMPOSITE FACES). WHERE 1 BTU-IN./HR FT ${ }^{2} \mathrm{~F}$

$=3.44482 \times 10^{-4} \mathrm{CAL} / \mathrm{s} \mathrm{cM}{ }^{0} \mathrm{C}$. 


\section{ORIGINAL PAGE IS \\ OF POOR QUALTY}

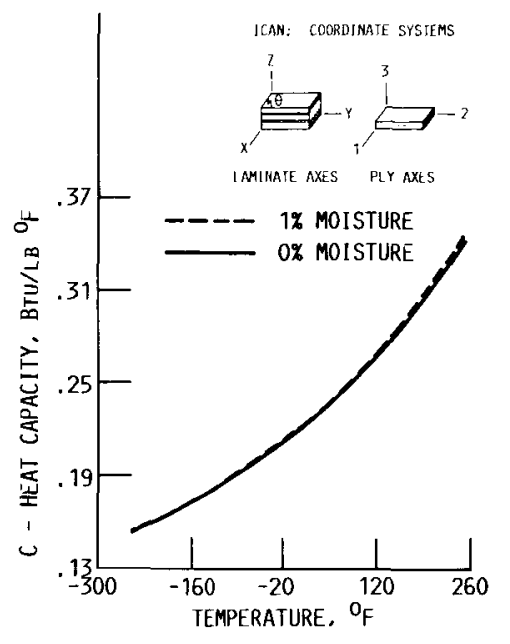

FIGURE 17. - HEAT CAPACITY FOR THE COMPOSITE SANDWICH STRUCTURE (ALU MINUM HONEYCOMB CORE AND $(0 / 90)$ S

P75/934 COMPOSITE FACES), WHERE

$1 \mathrm{BTU} / \mathrm{LB}{ }^{\circ} \mathrm{F}=4184 \mathrm{~J} / \mathrm{KG} \mathrm{K}$.

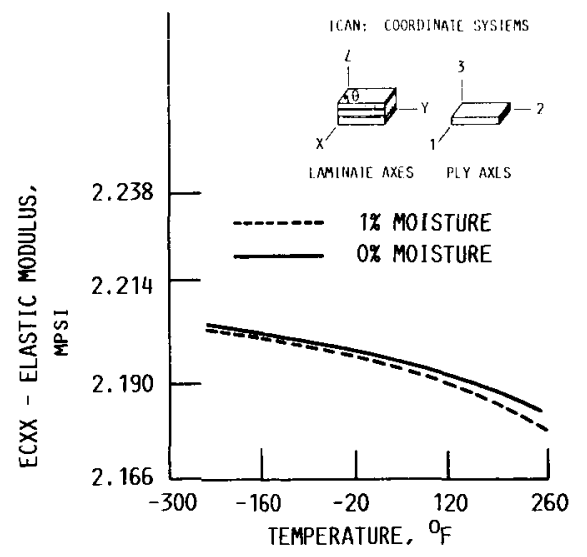

FIGURE 18. - ELASTIC MODULUS FOR THE COMPOSITE SANDWICH STRUCTURE (ALUMINUM HONEYCOMB CORE AND $(0 / 90)_{S}$ P75/934 COMPOSITE

FACES), WHERE 1 MPSI $=6.895$ GPA. 


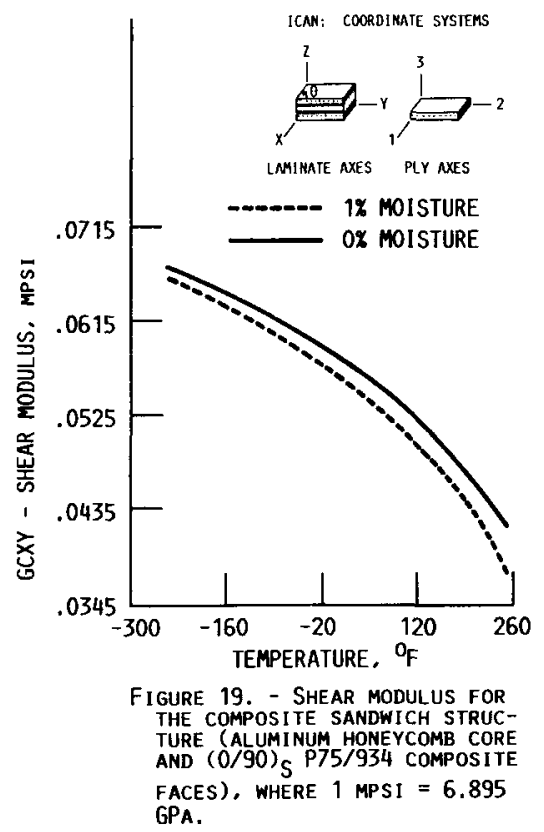




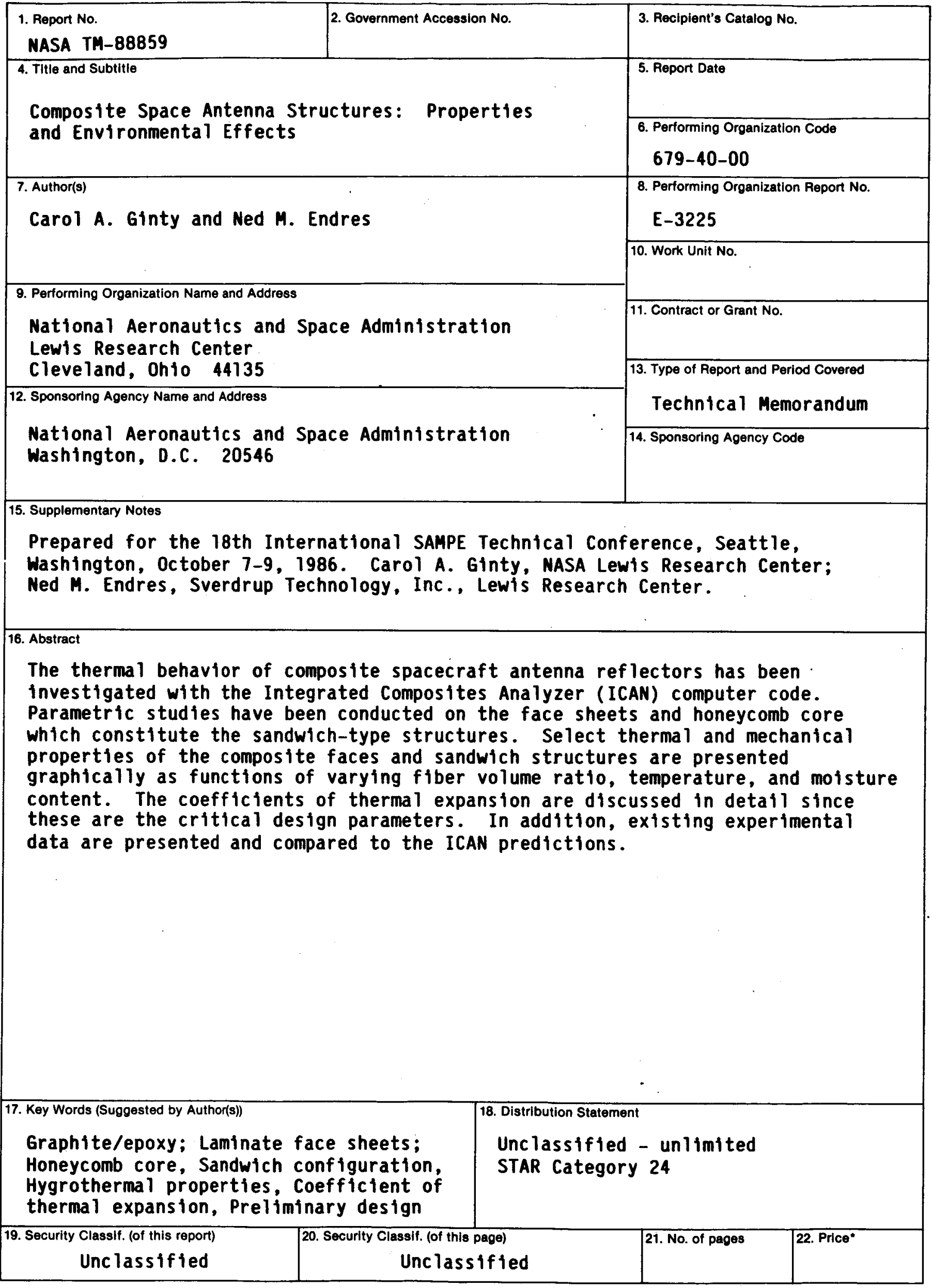

"For sale by the National Technical Information Service, Springfield, Virginia 22161 